\title{
PENERAPAN PENDIDIKAN KARAKTER UNTUK MEMBANGUN KEBERADABAN BANGSA
}

\author{
Alfian Mauricefle \\ Email: alfian.mauricefle@umbjm.ac.id \\ Fakultas Psikologi Universitas Muhammadiyah Banjarmasin \\ Jalan Gubernur Sarkawi, Handil Bakti, Barito Kuala Kalimantan Selatan
}

\begin{abstract}
ABSTRAK
Penelitian ini akan mengarahkan pada sasaran pendidikan karakter di sekolah. Sasaran pendidikan karakter adalah seluruh sekolah di Indonesia terutama pada tingkat SMP negeri maupun swasta, karena di masa SMP peserta didik belum terlalu melawan kepada guru, seperti anak SMA, dan anak SMP tidak terlalu kecil untuk mendapatkan materi pendidikan karakter, seperti anak SD. Semua warga sekolah, meliputi para peserta didik, guru, karyawan administrasi, dan pimpinan sekolah menjadi sasaran program ini. Sekolah-sekolah yang selama ini telah berhasil melaksanakan pendidikan karakter dengan baik dijadikan sebagai best practices, yang menjadi contoh untuk disebarluaskan ke sekolah-sekolah lainnya.

Kata Kunci: Pendidikan Karakter, Membangun Keberadaban Bangsa
\end{abstract}

\begin{abstract}
This research will lead to the target of character education in schools. The target of character education is all schools in Indonesia, especially at the public and private junior high school level, because in junior high school students are not too resistant to teachers, such as high school students, and junior high school children are not too young to get character education materials, such as elementary school children. All school residents, including students, teachers, administrative staff, and school leaders are the targets of this program. Schools that have been successful in carrying out character education well are used as best practices, which serve as examples to be disseminated to other schools.
\end{abstract}

Keywords: Character Education, Building Civilization of the Nation

\section{PENDAHULUAN}

Indonesia memerlukan sumber daya manusia dalam jumlah dan mutu yang memadai sebagai pendukung utama dalam pembangunan. Untuk memenuhi sumber daya manusia tersebut, pendidikan memiliki peran yang sangat penting.

Hal ini sesuai dengan UU No 20 Tahun 2003 Tentang Sistem Pendidikan Nasional pada Pasal 3 , yang menyebutkan bahwa pendidikan nasional berfungsi mengembangkan kemampuan dan membentuk karakter serta peradaban bangsa yang bermartabat dalam rangka mencerdaskan kehidupan bangsa. Pendidikan nasional bertujuan untuk berkembangnya potensi peserta didik agar menjadi manusia yang beriman dan bertakwa kepada Tuhan Yang Maha Esa, berakhlak mulia, sehat, berilmu, cakap, kreatif, mandiri, dan menjadi warga negara yang demokratis serta bertanggung jawab. 
Berdasarkan fungsi dan tujuan pendi- dikan nasional, jelas bahwa pendidikan di setiap jenjang, termasuk di sekolah harus diselenggarakan secara sistematis guna mencapai tujuan tersebut. Hal tersebut berkaitan dengan pembentukan karakter peserta didik sehingga mampu bersaing, beretika, bermoral, sopan santun dan berinteraksi dengan masyarakat. Berdasarkan penelitian di Harvard University Amerika Serikat (Ali Ibrahim Akbar, 2000), ternyata kesuksesan seseorang tidak ditentukan semata-mata oleh pengetahuan dan kemampuan teknis (hard skill) saja, tetapi lebih oleh kemampuan mengelola diri dan orang lain (soft skill). Penelitian ini mengungkapkan, kesuksesan hanya ditentukan sekitar 20 persen oleh hard skill dan sisanya 80 persen oleh soft skill. Bahkan orang-orang tersukses di dunia bisa berhasil dikarenakan lebih banyak didukung kemampuan soft skill daripada hard skill. Hal ini mengisyaratkan bahwa mutu pendidikan karakter peserta didik sangat penting untuk ditingkatkan. Melihat masyarakat Indonesia sendiri juga lemah sekali dalam penguasaan soft skill. Untuk itu penulis menulis makalah ini, agar pembaca tahu betapa pentingnya pendidikan karakter bagi semua orang, khususnya bangsa Indonesia sendiri.

\section{HASIL PENELITIAN DAN PEMBAHASAN \\ Pengertian Pendidikan Karakter}

Karakter merupakan nilai-nilai perilaku manusia yang berhubungan dengan Tuhan Yang Maha Esa, diri sendiri, sesama manusia, lingkungan, dan kebangsaan yang terwujud dalam pikiran, sikap, perasaan, perkataan, dan perbuatan berdasarkan norma-norma agama, hukum, tata krama, budaya, dan adat istiadat.

Pendidikan karakter adalah suatu sistem penanaman nilai-nilai karakter kepada warga sekolah yang meliputi komponen pengetahuan, kesadaran atau kemauan, dan tindakan untuk melaksanakan nilai-nilai tersebut, baik terhadap Tuhan Yang Maha Esa (YME), diri sendiri, sesama, lingkungan, maupun kebangsaan sehingga menjadi manusia insan kamil. Dalam pendidikan karakter di sekolah, semua komponen (stakeholders) harus dilibatkan, termasuk komponen-komponen pendidikan itu sendiri, yaitu isi kurikulum, proses pembelajaran dan penilaian, kualitas hubungan, penanganan atau pengelolaan mata pelajaran, pengelolaan sekolah, pelaksanaan aktivitas atau kegiatan ko-kurikuler, pemberdayaan sarana prasarana, pembiayaan, dan ethos kerja seluruh warga dan lingkungan sekolah.

"Pendidikan karakter yang utuh dan menyeluruh tidak sekedar membentuk anak-anak muda menjadi pribadi yang cerdas dan baik, melainkan juga membentuk mereka menjadi pelaku baik bagi perubahan dalam hidupnya sendiri, yang pada gilirannya akan menyumbangkan perubahan dalam tatanan sosial kemasyarakatan menjadi lebih adil, baik, dan manusiawi" (Doni KoesoemaAM.Ed)

\section{Pendidikan Karakter Untuk Membangun Keberadaban Bangsa}

Dunia pendidikan diharapkan sebagai motor penggerak untuk memfasilitasi perkembangan karakter, sehingga anggota masyarakat mempunyai kesadaran kehidupan berbangsa dan bernegara yang harmonis dan demokratis dengan tetap memperhatikan sendi-sendi Negara Kesatuan Republik Indonesia (NKRI) dan norma-norma sosial di masyarakat yang telah menjadi kesepakatan bersama.

Dari mana asalmu tidak penting, ukuran tubuhmu juga tidak penting, ukuran Otakmu cukup penting, ukuran hatimu itulah yang sangat penting karena otak (pikiran) dan kalbu hati yang paling kuat menggerak seseorang itu "bertutur kata dan bertindak". Simak, telaah, 
dan renungkan dalam hati apakah telah memadai "wahana" pembelajaran memberikan peluang bagi peserta didik untuk multi kecerdasan yang mampu mengembangkan sikap-sikap: kejujuran, integritas, komitmen, kedisipilinan, visioner, dan kemandirian.

Sejarah memberikan pelajaran yang amat berharga, betapa perbedaan, pertentangan, dan pertukaran pikiran itulah sesungguhnya yang mengantarkan kita ke gerbang kemerdekaan. Melalui perdebatan tersebut kita banyak belajar, bagaimana toleransi dan keterbukaan para Pendiri Republik ini dalam menerima pendapat, dan berbagai kritik saat itu. Melalui pertukaran pikiran itu kita juga bisa mencermati, betapa kuat keinginan para Pemimpin Bangsa itu untuk bersatu di dalam satu identitas kebangsaan, sehingga perbedaan-perbedaan tidak menjadi persoalan bagi mereka.

Karena itu pendidikan karakter harus digali dari landasan idiil Pancasila, dan landasan konstitusional UUD 1945. Sejarah Indonesia memperlihatkan bahwa pada tahun 1928, ikrar "Sumpah Pemuda" menegaskan tekad untuk membangun nasional Indonesia. Mereka bersumpah untuk berbangsa, bertanah air, dan berbahasa satu yaitu Indonesia. Ketika merdeka dipilihnya bentuk negara kesatuan. Kedua peristiwa sejarah ini menunjukan suatu kebutuhan yang secara sosio-politis merefleksi keberadaan watak pluralisme tersebut. Kenyataan sejarah dan sosial budaya tersebut lebih diperkuat lagi melalui arti symbol "Bhineka Tunggal Ika" pada lambang negara Indonesia.

Dari mana memulai dibelajarkannya nilai-nilai karakter bangsa, dari pendidikan informal, dan secara pararel berlanjut pada pendidikan formal dan nonformal. Tantangan saat ini dan ke depan bagaimana kita mampu menempatkan pendidikan karakter sebagai sesuatu kekuatan bangsa. Oleh karena itu kebijakan dan implementasi pendidikan yang berbasiskaraktermenjadi sangat penting dan strategis dalam rangka membangun bangsa ini. Hal ini tentunya juga menuntut adanya dukungan yang kondusif dari pranata politik, sosial, dan budaya bangsa.

"Pendidikan Karakter Untuk Membangun Keberadaban Bangsa" adalah kearifan dari keaneragaman nilai dan budaya kehidupan bermasyarakat. Kearifan itu segera muncul, jika seseorang membuka diri untuk menjalani kehidupan bersama dengan melihat realitas plural yang terjadi. Oleh karena itu pendidikan harus diletakan pada posisi yang tepat, apalagi ketika menghadapi konflik yang berbasis pada ras, suku dan keagamaan. Pendidikan karakter bukanlah sekedar wacana tetapi realitas implementasinya, bukan hanya sekedar kata-kata tetapi tindakan dan bukan simbol atau slogan, tetapi keberpihak yang cerdas untuk membangun keberadaban bangsa Indonesia. Pembiasaan berperilaku santun dan damai adalah refreksi dari tekad kita sekali merdeka, tetap merdeka. (Muktiono Waspodo).

Upaya Meningkatkan Mutu Pendidikan Karakter Terlepas dari berbagai kekurangan dalam praktik pendidikan di Indonesia, apabila dilihat dari standar nasional pendidikan yang menjadi acuan pengembangan kurikulum (KTSP), dan implementasi pembelajaran dan penilaian di sekolah, tujuan pendidikan sebenarnya dapat dicapai dengan baik. Pembinaan karakter juga termasuk dalam materi yang harus diajarkan dan dikuasai serta direalisasikan oleh peserta didik dalam kehidupan sehari-hari. Permasalahannya, pendidikan karakter di sekolah selama ini baru menyentuh pada tingkatan pengenalan norma atau nilai-nilai, dan belum pada tingkatan internalisasi dan tindakan nyata dalam kehidupansehari-hari.

Sebagai upaya untuk meningkatkan kesesuaian dan mutu pendidikan karakter, Kementerian Pendidikan Nasional mengembangkan grand design pendidikan karakter untuk setiap jalur, jenjang, dan jenis satuan pendidikan. Grand design menjadi rujukan konseptual dan operasional pengembangan, pelaksanaan, dan penilaian pada setiap jalur 
dan jenjang pendidikan. Konfigurasi karakter dalam konteks totalitas proses psikologis dan sosial-kultural tersebut dikelompokan dalam: Olah Hati (Spiritual and emotional development), Olah Pikir (intellectual development), Olah Raga dan Kinestetik (Physical and kinestetic development), dan Olah Rasa dan Karsa (Affective and Creativity development). Pengembangan dan implementasi pendidikan karakter perlu dilakukan dengan mengacu pada grand design tersebut.

Menurut UU No 20 Tahun 2003 Tentang Sistem Pendidikan Nasional pada Pasal 13 Ayat 1 menyebutkan bahwa Jalur pendidikan terdiri atas pendidikan formal, nonformal, dan informal yang dapat saling melengkapi dan memperkaya. Pendidikan informal adalah jalur pendidikan keluarga dan lingkungan. Pendidikan informal sesungguhnya memiliki peran dan kontribusi yang sangat besar dalam keberhasilan pendidikan. Peserta didik mengikuti pendidikan di sekolah hanya sekitar 7 jam per hari, atau kurang dari 30\%. Selebihnya (70\%), peserta didik berada dalam keluarga dan lingkungan sekitarnya. Jika dilihat dari aspek kuantitas waktu, pendidikan di sekolah berkontribusi hanya sebesar 30\% terhadap hasil pendidikan peserta didik.

Selama ini, pendidikan informal terutamadalam lingkungankeluargabelum memberikan kontribusi berarti dalam mendukung pencapaian kompetensi dan pembentukan karakter peserta didik. Kesibukan dan aktivitas kerja orang tua yang relatif tinggi, kurangnya pemahaman orang tua dalam mendidik anak di lingkungan keluarga, pengaruhpergaulan di lingkungan sekitar, dan pengaruh media elektronik ditengarai bisa berpengaruh negatif terhadap perkembangan dan pencapaian hasil belajar peserta didik. Salah satu alternatif untuk mengatasi permasalahan tersebut adalah melalui pendidikan karakter terpadu, yaitu memadukan dan mengopti- malkan kegiatan pendidikan informal lingkungan keluarga dengan pendidikan formal di sekolah. Dalam hal ini, waktu belajar peserta didik di sekolah perlu dioptimalkan agar peningkatan mutu hasil belajar dapat dicapai, terutama dalam pembentukan karakter peserta didik.

Sasaran pendidikan karakter adalah seluruh sekolah di Indonesia terutama pada tingkat SMP negeri maupun swasta, karena di masa SMP peserta didik belum terlalu melawan kepada guru, seperti anak SMA, dan anak SMP tidak terlalu kecil untuk mendapatkan materi pendidikan karakter, seperti anak SD. Semua warga sekolah, meliputi para peserta didik, guru, karyawan administrasi, dan pimpinan sekolah menjadi sasaran program ini. Sekolah-sekolah yang selama ini telah berhasil melaksanakan pendidikan karakter dengan baik dijadikan sebagai best practices, yang menjadi contoh untuk disebarluaskan ke sekolah-sekolah lainnya.

Pendidikan karakter bertujuan untuk meningkatkan mutu penyelenggaraan dan hasil pendidikan di sekolah yang mengarah pada pencapaian pembentukan karakter dan akhlak mulia peserta didik secara utuh, terpadu, dan seimbang. Melalui pendidikan karakter diharapkan peserta didik mampu secara mandiri meningkatkan dan menggunakan pengetahuannya, mengkaji dan menginternalisasi serta mempersonalisasi nilai-nilai karakter dan akhlak mulia sehingga terwujud dalam perilaku sehari- hari.

Menurut Mochtar Buchori (2007), pendidikan karakter seharusnya membawa peserta didik ke pengenalan nilai secara kognitif, penghayatan nilai secara afektif, dan akhirnya ke pengamalan nilai secara nyata. Permasalahan pendidikan karakter yang selama ini ada di SMP perlu segera dikaji, dan dicari altenatif-alternatif solusi- nya, serta perlu dikembangkannya secara lebih operasional sehingga mudah diimplementasikan disekolah.

Melalui program ini diharapkan lulusan-lulusan dari peserta didik dapat memiliki keimanan dan ketaqwaan kepada Tuhan Yang Maha Esa, berakhlak mulia, berkarakter mulia, 
kompetensi akademik yang utuh dan terpadu, sekaligus memiliki kepribadian yang baik sesuai norma-norma dan budaya Indonesia. Pada tataran yang lebih luas, pendidikan karakter nantinya diharapkan menjadi budaya sekolah.

\section{Pendidikan Karakter Yang Berhasil}

Keberhasilan program pendidikan karakter dapat diketahui melalui pencapaian indikator oleh peserta didik sebagaimana tercantum dalam Standar Kompetensi Lulusan SMP, yang antara lain meliputi sebagai berikut:

1. Mengamalkan ajaran agama yang dianut sesuai dengan tahap perkembangan remaja

2. Memahami kekurangan dan kelebihan diri sendiri.

3. Menunjukkan sikap percaya diri.

4. Mematuhi aturan-aturan sosial yang berlaku dalam lingkungan yang lebih luas.

5. Menghargai keberagaman agama, budaya, suku, ras, dan golongan sosial ekonomi dalam lingkup nasional.

6. Mencari dan menerapkan informasi dari lingkungan sekitar dan sumber-sumber lain secara logis, kritis, dan kreatif.

7. Menunjukkan kemampuan berpikir logis, kritis, kreatif, dan inovatif.

8. Menunjukkan kemampuan belajar secara mandiri sesuai dengan potensi yang dimilikinya.

9. Menunjukkan kemampuan menganalisis dan memecahkan masalah dalam kehidupan seharihari.

10. Mendeskripsikan gejala alam dan social.

11. Memanfaatkan lingkungan secara bertanggung jawab.

12. Menerapkan nilai-nilai kebersamaan dalam kehidupan bermasyarakat, berbangsa, dan bernegara demi terwujudnya persatuan dalam negara kesatuan Republik Indonesia.

13. Menghargai karya seni dan budaya nasional.

14. Menghargai tugas pekerjaan dan memiliki kemampuan untuk berkarya.

15. Menerapkan hidup bersih, sehat, bugar, aman, dan memanfaatkan waktu luang dengan baik.

16. Berkomunikasi dan berinteraksi secara efektif dan santun.

17. Memahami hak dan kewajiban diri dan orang lain dalam pergaulan di masyarakat; Menghargai adanya perbedaan pendapat.

18. Menunjukkan kegemaran membaca dan menulis naskah pendek sederhana.

19. Menunjukkan keterampilan menyimak, berbicara, membaca, dan menulis dalam bahasa Indonesia dan bahasa Inggris sederhana.

20. Menguasai pengetahuan yang diperlukan untuk mengikuti pendidikan menengah.

21. Memiliki jiwa kewirausahaan.

Pada tataran sekolah, kriteria pencapaian pendidikan karakter adalah terbentuknya budaya sekolah, yaitu perilaku, tradisi, kebiasaan keseharian, dan simbol-simbol yang dipraktikkan oleh semua warga sekolah, dan masyarakat sekitar sekolah harus berlandaskan nilai-nilai tersebut.

\section{KESIMPULAN}

Dari pembahasan di atas penulis dapat disimpulkan sebagai berikut yaitu: 
1. Bangsa Indonesia telah berusaha untuk meningkatkan kesesuaian dan mutu pendidikan karakter melalui sekolah-sekolah, terutama Sekolah Menengah Pertama (SMP), karena anak usia SMP sangat cocok untuk diberi pembelajaran tentang pendidikan karakter.

2. Guru adalah orang tua para siswa. Kare- nanya, Rosulullah melarang para orangtua (guru) mendoakan keburukan bagi anak-didiknya. Mendoakan keburukan kepada anak merupakan hal yang berbahaya. Dapat mengakibatkan kehancuran anak dan masa depannya.

3. Pendidikan karakter bertujuan untuk meningkatkan mutu penyelenggaraan dan hasil pendidikan di sekolah yang mengarah pada pencapaian pembentukan karakter dan akhlak mulia peserta didik secara utuh, terpadu, dan seimbang. Bila pendidikan karakter telah mencapai keberhasilan, tidak diragukan lagi kalau masa depan bangsa Indonesia ini akan mengalami perubahan menuju kejayaan. Dan bilapendidikan karakter ini mengalami kegagalan sudah pasti dampaknya akan sangat besar bagi bangsa ini, negara kita akan semakin ketinggalan dari negara-negara lain.

\section{DAFTAR PUSTAKA}

Agustina AG, 2009. Bangkit Dengan 7 Budi Utama. Jakarta: Arga Publishing

Budimansyah, 2010. Penguatan Pendidikan Kewarganegaraan Untuk Membangun Karakter Bangsa. Bandung: Widya Angkasa Press

Dharma Kusuma. dkk, 2011. Pendidikan Karakter Kajian Teori dan Praktik di Sekolah. Bandung: Remaja Rosdakarya

Masnur Muslich, 2011. Pendidikan Karakter Menjawab Tantangan Krisis Multidimen- sional. Jakarta: Bumi Aksara

Megawati Ratna, 2004. Pendidikan Karakter Solusi yang Tepat untuk Membangun Bangsa. Jakarta: BPMIGAS

Nurla Isna Aunillah, 2011. Panduan Menerapkan Pendidikan Karakter di Sekolah. Yogyakarta: Laksana

Novan Ardy Wiyani, 2012. Manajemen Pendidikan Karakter. Yogyakarta: Pedagogia.

Nunung Nursyamsiah. Rencana Disertasi Pengembangan dan Pembudayaan Nilai Berorientasi Konsep Pendidikan untuk Pembangunan Berkelanjutan (PPB) melalui Implementasi Lesson Study Berbasis Sekolah. Prodi Pendidikan Umum Sekolah Pasca Sarjana Universitas Pendidikan Indonesia 2008, 5-6

Rohinah M. Noor. 2012. Mengembangkan Karakter Anak Secara Efektif di Sekolah dan di Rumah. (Yogyakarta: PEDAGOGIA (PT. Pustaka Insan Madani, Anggota IKAPI) Cetakan Pertama, Januari )

Rohinah M. Noor. 2012. The Hidden Curriculum Membangun Karakter Melalui Kegiatan Ekstrakurikuler. Cetakan Pertama, Januari, (Insan Madani, Jalan Kenanga, Mangunharjo, Depok, Sleman, Yogyakarta 55282). 59-60

Rukiyati, Urgensi Pendidikan Karakter Holistik Komprehensif di Indonesia, Jurnal Pendidikan Karakter, Tahun III, Nomor 2, Juni 2013, 197

Soedarsono, 2009. Karakter Mengantar Bangsa Dari Gelap Menuju Terang. Jakarta: Gramedia 